International Journal of Molecular Sciences ISSN 1422-0067

www.mdpi.com/journal/ijms

Article

\title{
The Effect of Self-Assembling Peptide RADA16-I on the Growth of Human Leukemia Cells in Vitro and in Nude Mice
}

\author{
Chengkang Tang ${ }^{1}$, Ximing Shao ${ }^{1}$, Binbin Sun ${ }^{1}$, Wenli Huang ${ }^{1}$ and Xiaojun Zhao ${ }^{1,2,3, *}$
}

1 Institute for Nanobiomedical Technology and Membrane Biology, West China Hospital, Sichuan University, Chengdu, 610041, China; E-Mails: tangck@126.com (C.T.); shaoximing07@163.com (X.S.); sunbb@163.com (B.S.); huangwenli133@163.com (W.H.)

2 West China Medical School, West China Hospital, Sichuan University, Guo Xue Xiang 37 , Chengdu, 610041, Chengdu, China

3 Center for Biomedical Engineering, NE47-379, Massachusetts Institute of Technology, Cambridge, MA 02139-4307, USA

* Author to whom correspondence should be addressed; E-mails: xiaojunz@mit.edu; Tel. +86-28-8516-4069; Fax: +86-28-8516-4070

Received: 31 March 2009; in revised form: 30 April 2009 / Accepted: 12 May 2009 /

Published: 14 May 2009

\begin{abstract}
Nanofiber scaffolds formed by self-assembling peptide RADA16-I have been used for the study of cell proliferation to mimic an extracellular matrix. In this study, we investigated the effect of RADA16-I on the growth of human leukemia cells in vitro and in nude mice. Self-assembly assessment showed that RADA16-I molecules have excellent self-assembling ability to form stable nanofibers. MTT assay displayed that RADA16-I has no cytotoxicity for leukemia cells and human umbilical vein endothelial cells (HUVECs) in vitro. However, RADA16-I inhibited the growth of K562 tumors in nude mice. Furthermore, we found RADA16-I inhibited vascular tube-formation by HUVECs in vitro. Our data suggested that nanofiber scaffolds formed by RADA16-I could change tumor microenvironments, and inhibit the growth of tumors. The study helps to encourage further design of self-assembling systems for cancer therapy.
\end{abstract}

Keywords: self-assembling peptide RADA16-I; nanofiber scaffolds; mimic extracellular matrix; tumor microenvironments; cancer therapy 


\section{Introduction}

For a long time, many efforts have focused on the inhibition and destruction of cancer cells for cancer treatment, but unfortunately, because of drug cytotoxicity and resistance developed in cancer cells, the applications of many traditional anticancer drugs are generally accompanied with inefficiencies and severe side effects [1,2].

Recently, researchers realized that solid tumors are organ-like structures in various microenvironments; cancer cells are embedded in an extracellular matrix and nourished by a vascular network. These microenvironments not only allow interactions among cancer cells and between cancer cells and the basal membrane, but also remove waste products. Substantial studies have determined that tumor microenvironments are critical for the proliferation of tumor cells and their response to anticancer drugs [3-5]. Thus, strategies to modulate the tumor microenvironments (including the tumor vasculature) could offer additional approaches for cancer treatment.

Previous studies have discovered that self-assembling peptide systems [6-13], made from natural amino acids, can spontaneously assemble into nanofiber scaffolds, which comprise numerous nanofibers of $\sim 10 \mathrm{~nm}$ diameter and nanopores between $5-200 \mathrm{~nm}$ [6-8]. These peptide scaffolds have three-dimensional nanofiber structures similar to the natural extracellular matrix. Consequently, they have been used for the study of cell attachment and proliferation as biomimic synthetic extracellular matrix $[7,9,10]$.

The self-assembling peptide RADA16-I (Ac-RADARADARADARADA-CONH 2 ), a simple model oligopeptide, is characterized by the regular repeats of alternating ionic hydrophilic and hydrophobic amino acids, and usually forms stable a $\beta$-sheet structure in water. RADA16-I molecules can not only spontaneously self-assemble to form stable nanofibers, but also form higher-order nanofiber scaffolds in the presence of monovalent cations or physiological media [8]. Here, we asked whether nanofiber scaffolds formed by RADA16-I could change the tumor microenvironments as biomimetic extracellular matrix, and influence the growth of tumors.

In this study, we firstly confirmed the self-assembling ability of RADA16-I by using atomic force microscopy (AFM). Secondly, MTT assay was performed to examine the effect of RADA16-I on the proliferation of human leukemia cells and human umbilical vein endothelial cells (HUVECs) in vitro. We next examined the inhibition of RADA16-I against human leukemia xenograft growth in nude mice. Finally, we evaluated the in vitro effect of RADA16-I on the vascular tube-formation by HUVECs, which are critical to form new capillaries in the vicinity of solid tumors and promote the formation of three-dimensional vascular tubes $[14,15]$.

\section{Results and Discussion}

\subsection{Self-assembly Assessment of RADA16-I}

The self-assembling peptide RADA16-I (Figure 1) is a self-complementary peptide, which forms stable $\beta$-sheet structure in aqueous solution with two distinct surfaces - one hydrophilic, the other hydrophobic. All the hydrophobic alanine residues shield themselves from water and self-assemble on the hydrophobic surface, on the other hand, arginine and aspartic acid residues can form 
complementary ionic bonds with regular repeats on the hydrophilic surface. Based on these intermolecular forces, RADA16-I molecules can spontaneously self-assemble to form stable nanofibers and higher-order nanofiber scaffolds in physiological media.

Figure 1. Schematic molecular model of Peptide RADA16-I. RADA16-I has regular repeats of ionic hydrophilic and hydrophobic amino acids, and forms stable $\beta$-sheet structure in aqueous solution with two distinct surfaces - hydrophilic surface and hydrophobic surface. All the hydrophobic alanine residues form the hydrophobic surface, arginine and aspartic acid residues constitute the hydrophilic surface with regular repeats. The dimensions of the RADA16-I molecule are about $5 \mathrm{~nm}$ in length, $1.3 \mathrm{~nm}$ in height, and $0.8 \mathrm{~nm}$ in width [16].

RADA16-I: AC-RADARADARADARADA-CONH

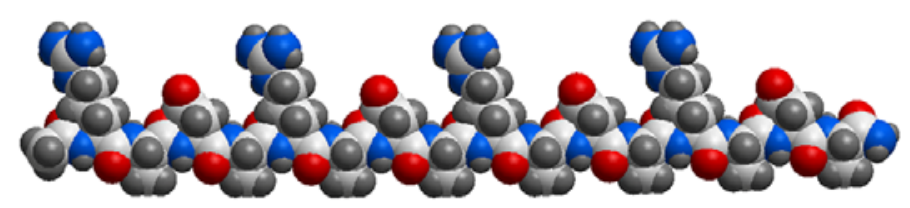

In this study, the nanostructure of RADA16-I was observed by using AFM (Tapping Mode) at different scales $\left(5 \times 5 \mu \mathrm{m}^{2}, 2 \times 2 \mu \mathrm{m}^{2}\right.$ and $\left.1 \times 1 \mu \mathrm{m}^{2}\right)$. As shown in Figure 2, dense nanofibers formed by RADA16-I were observed, a result consistent with a previous study [17]. The result confirms that peptide RADA16-I has excellent self-assembling ability to form nanofibers and higher-order nanofiber scaffolds.

Figure 2. AFM images of RADA16-I. The working solution of RADA16-I was prepared at $100 \mu \mathrm{M}$ concentration by using Milli-Q water. The nanostructure of RADA16-I was scanned at different scales, $5 \times 5 \mu \mathrm{m}^{2}(\mathrm{~A}), 2 \times 2 \mu \mathrm{m}^{2}$ (B) and $1 \times 1 \mu \mathrm{m}^{2}$ (C). Dense nanofibers were observed, indicating peptide RADA16-I has excellent self-assembling ability to form nanofiber scaffolds.
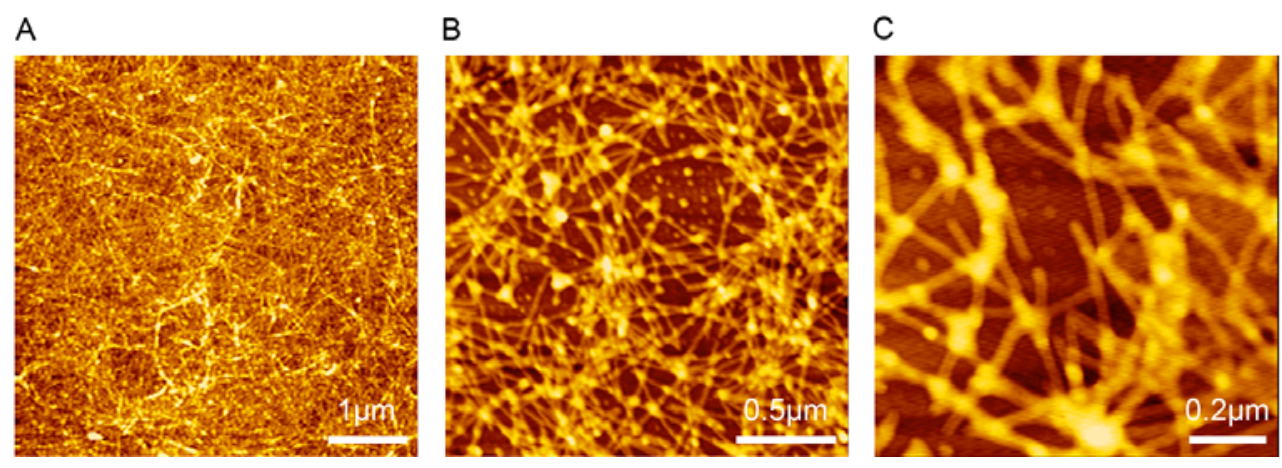

\subsection{Cytotoxicity Assays in vitro}

Previous studies have shown that nanofiber scaffolds formed by self-assembling peptides have no cytotoxicity, and support the attachment and growth of a variety of mammalian primary cells in tissue 
culture [6-8]. Similarly, RADA16-I is nontoxic and supports not only the growth of cells [8], but also tissue regeneration [18]. The results of a MTT assay are consistent with early studies, showing that RADA16-I had no cytotoxicity for both K562 and Jurkat cells even at $2 \mathrm{mM}$ peptide concentration; the relative viabilities were $101.66 \pm 4.25 \%$ for K562 cells and $97.44 \pm 5.66 \%$ for Jurkat cells (Figure 3A). RADA16-I even promoted the growth of leukemia cells at lower peptide concentrations (Figure 3A). Moreover, MTT assay also showed that RADA16-I had no cytotoxicity against HUVECs, there was almost no reduction in HUVEC viability (90 - 100\% viability) after treatment with peptide RADA16-I at varying concentrations $((10-80 \mu \mathrm{M})$ (Figure 3B). Taken together, the results of MTT assay suggested that peptide RADA16-I had an excellent biocompatibility without obvious cytotoxicity as described $[8,18]$.

Figure 3. Cytotoxicity of RADA16-I against human leukemia cells and HUVECs by MTT proliferation assay. (A) MTT assay showed that RADA16-I had no cytotoxicity for both K562 and Jurkat cells. After treated with RADA16-I solution at the maximal concentration $(2 \mathrm{mM})$, the relative viabilities of K562 and Jurkat cells were $101.66 \pm 4.25 \%$ and $97.44 \pm$ $5.66 \%$, respectively. RADA16-I solutions at lower concentrations even enhanced the proliferation of cells. (B) MTT assay displayed that RADA16-I had almost no cytotoxicity against HUVECs even at $80 \mu \mathrm{M}$ peptide concentration $(92.90 \pm 3.54 \%$ viability). Data shown are Means \pm SD.
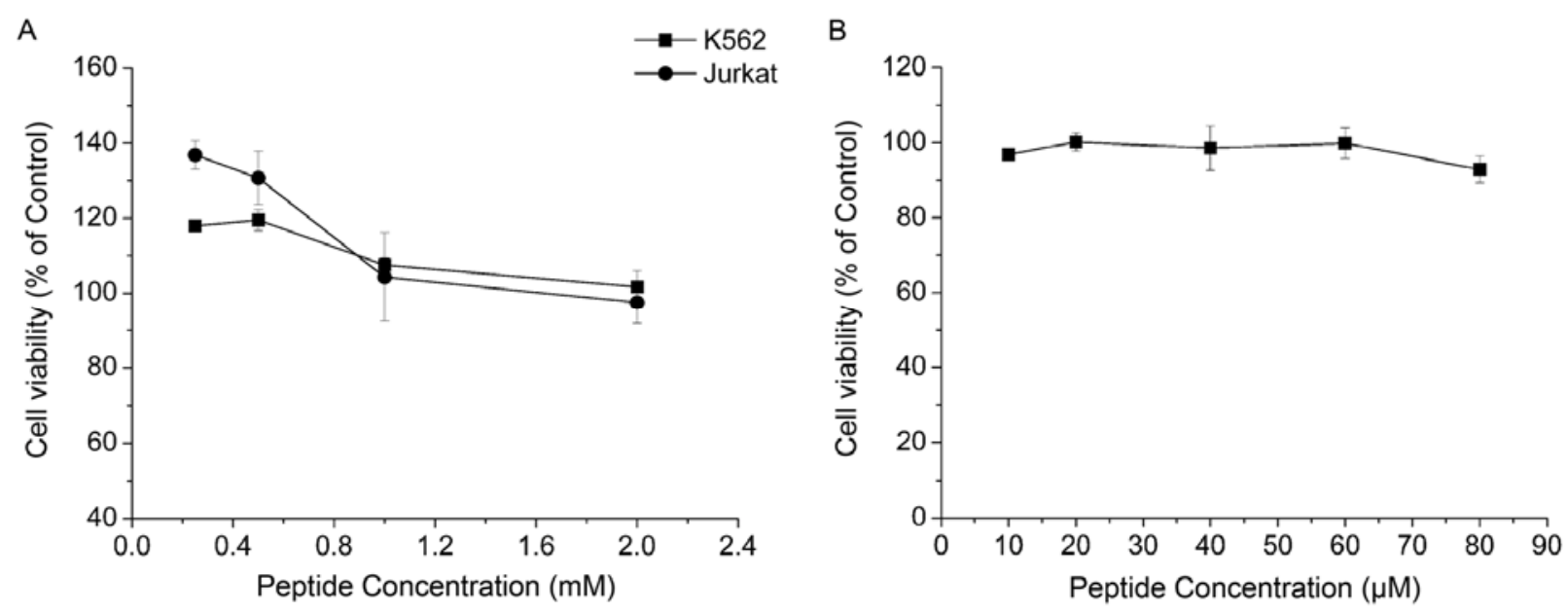

\subsection{Inhibition of RADA16-I on K562 Tumor Growth in vivo}

After examining the cytotoxicity of RADA16-I against leukemia cells in vitro, we further analyzed the effect of RADA16-I on the growth of K562 tumors in nude mice. After the sixth treatment, we found that the average tumor weight $(1.51 \pm 0.08 \mathrm{~g})$ in RADA16-I treatment group had been markedly decreased, compared with that $(2.72 \pm 0.50 \mathrm{~g})$ in a control group (Figure 4A). Other than these effects, animals treated with RADA16-I were normal and did not show any sign of physical weakness throughout the experiment. Finally, tumors were fixed with formaldehyde, and sectioned for histological examination by $H \& E$ staining. As shown in Figure 4B, H\&E staining showed that mass proliferation existed in tumor cells from control mice, whereas the structural pattern of tumors treated with RADA16-I was replaced by massive cell death in which the cells were characterized by 
acidophilic homogeneous masses without nuclei. These data suggested that RADA16-I could inhibit the K562 tumor growth in vivo though peptide has no cytotoxicity against cancer cells in vitro.

Figure 4. Effect of RADA16-I on K562 tumor growth. We analyzed the effect of RADA16-I on K562 tumor growth by using mouse models. (A) After treatment with RADA16-I, average tumor weight in treatment group $(1.51 \pm 0.08 \mathrm{~g})$ was markedly decreased as compared with that in control group $(2.72 \pm 0.50 \mathrm{~g})$, data shown are Means \pm SEM, $\mathrm{P}<0.05$. (B) Histological examination of tumors. Tumors were fixed with formaldehyde, and sectioned for histological examination by $\mathrm{H} \& \mathrm{E}$ staining. $\mathrm{H} \& \mathrm{E}$ staining showed that massive cell death existed in tumors treated by RADA16-I compared with the controls. These results suggested that RADA16-I could inhibit the K562 tumor growth in vivo.

A
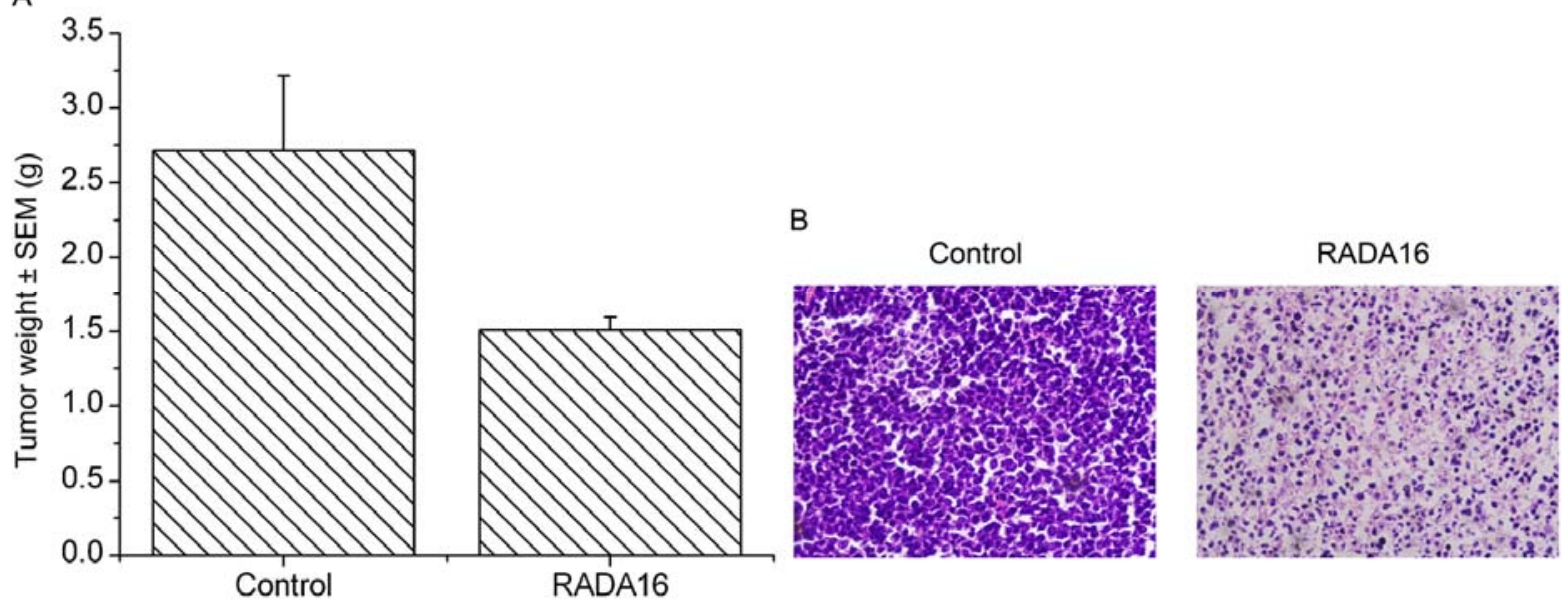

\subsection{Inhibition of Vascular Tube-formation by RADA16-I}

The formation of new capillaries by HUVEC is critical for the migration of endothelial cells and the formation of neovascularization [14]. In our study, we evaluated the effect of RADA16-I on tube formation by HUVECs. As seen in Figure 5, HUVECs without peptide treatment migrated to form a well-arranged network of tubes within $9 \mathrm{~h}$, while this effect was significantly decreased in the presence of RADA16-I. After treated with $20 \mu \mathrm{M}$ or $40 \mu \mathrm{M}$ RADA16-I, the endothelial network-like structures were broken. Furthermore, treatment with $60 \mu \mathrm{M}$ or $80 \mu \mathrm{M}$ RADA16-I yielded maximal inhibition with the almost complete absence of tube formation. However, MTT assay showed that RADA16-I is nontoxic to HUVECs even at $80 \mu \mathrm{M}$ peptide concentration (Figure 3B), suggesting the inhibition of vascular tube-formation is not caused by cell death or cytotoxicity. Taken together, these results indicated that RADA16-I could inhibit the formation of neovascularization without cytotoxic effect, and consequently lead to prevention of tumor growth. 
Figure 5. Inhibition of vascular tube-formation in vitro. We evaluated the effect of RADA16-I on the tubes formation by HUVECs in vitro. (A) HUVECs treated with control solution can migrate to form a well-arranged network of tubes within $9 \mathrm{~h}$. After treated with $20 \mu \mathrm{M}$ (B) or $40 \mu \mathrm{M}$ (C) RADA16-I, the network-like structures were broken. Treatment with $60 \mu \mathrm{M}$ (D) or $80 \mu \mathrm{M}$ (E) RADA16-I completely inhibited the tube formation. These data suggested that RADA16-I could inhibit the formation of vascular tubes.

A

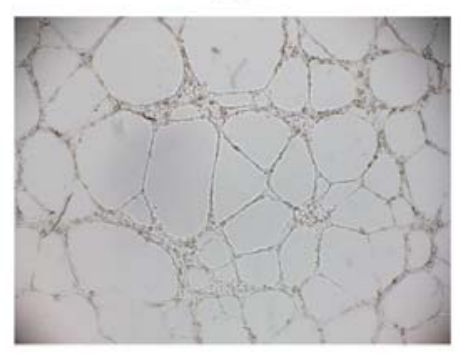

B

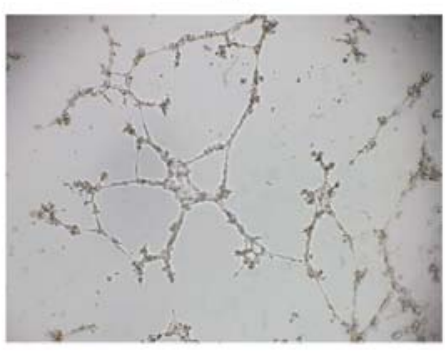

C

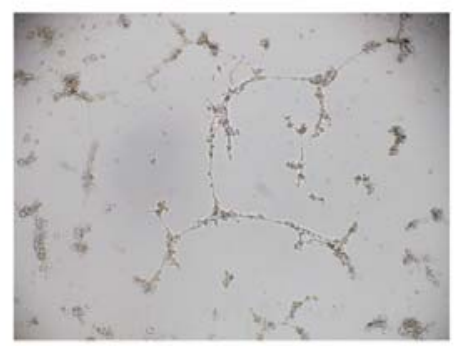

E
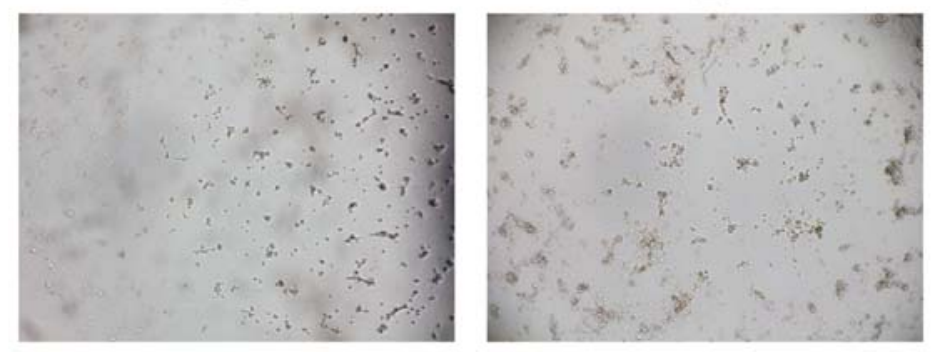

\section{Experimental Section}

\subsection{Preparation of Peptide RADA16-I}

The peptide RADA16-I (PuraMatrix ${ }^{\mathrm{TM}}$, Ac-RADARADARADARADA-CONH${ }_{2}$ ) was purchased from BD Bioscience (Bedford, MA, USA). The working solutions of RADA16-I were prepared at different concentrations with sterile water (18 M $\Omega$; Millipore Milli-Q system) and stored at $4{ }^{\circ} \mathrm{C}$.

\subsection{Cell Cultures}

Human umbilical vein endothelial cells (HUVECs) were isolated from human umbilical cord tissue by collagenase digestion as described previously [19]. The harvested cells were plated on gelatincoated culture bottles in medium 199 containing 20\% fetal calf serum, basic fibroblast growth factor (bFGF, $10 \mathrm{ng} / \mathrm{mL}$ ), vascular endothelial growth factor (VEGF, $2 \mathrm{ng} / \mathrm{mL}$ ), $200 \mathrm{U} / \mathrm{mL}$ penicillin and $200 \mu \mathrm{g} / \mathrm{mL}$ streptomycin. After $3-4$ passages, HUVECs were collected to use. Two human leukemia cell lines, K562 and Jurkat, were grown in RPMI 1640 medium supplemented with 10\% fetal calf serum and antibiotics (100 units/mL penicillin $\mathrm{G}, 100 \mu \mathrm{g} / \mathrm{mL}$ streptomycin). All cell lines were incubated at $37{ }^{\circ} \mathrm{C}$ in a $5 \% \mathrm{CO}_{2}$ humidified atmosphere. 


\subsection{Self-Assembly Assessment of RADA16-I with Atomic Force Microscopy}

RADA16-I working solution was prepared at a concentration of $100 \mu \mathrm{M}$ with Milli-Q water. Approximately $5 \mu \mathrm{L}$ of RADA16-I solution was evenly deposited onto a freshly cleaved mica surface at room temperature. After 30 seconds, the mica surface was rinsed with 1,000 $\mu \mathrm{L}$ of Milli-Q water to remove unattached peptides. Sample on the mica surface was then air-dried and scanned by Atomic Force Microscopy (AFM) in air.

AFM images were collected by using the tapping mode on a SPI4,000 Probe Station \& SPA-400 SPM Unit (Seiko Instruments Inc., Chiba, Japan). All images were acquired by utilizing a $20 \mu \mathrm{m}$ Scanner (400) and an Olympus Si-DF20 microcantilever as well as tip ( $\mathrm{Si}$, tip radius $10 \mathrm{~nm}$, rectangular base $200.00 \mu \mathrm{m}$ ) with the spring constant of $12.00 \mathrm{~N} / \mathrm{m}$. The cantilever's free resonance frequency is $127.00 \mathrm{KHz}$. To show the nanostructure formed by self-assembling peptide RADA16-I, AFM images were scanned and collected at $5 \times 5 \mu \mathrm{m}^{2}, 2 \times 2 \mu \mathrm{m}^{2}$ and $1 \times 1 \mu^{2}$ scales.

\subsection{MTT Proliferation Assay}

The effect of RADA16-I on the viability of human leukemia cells and HUVECs in vitro was assessed by a MTT assay [20]. Briefly, cells in $100 \mu \mathrm{L}$ of fresh medium were seeded onto 96-well plates at a density of $5 \times 10^{3}$ cells/well for K562, $2 \times 10^{4}$ cells/well for Jurkat and $1 \times 10^{4}$ cells/well for HUVECs, respectively. After $24 \mathrm{~h}$ incubation at $37{ }^{\circ} \mathrm{C}, 10 \mu \mathrm{L}$ of RADA16-I solution and control solution (sterile water) were added and incubated for $48 \mathrm{~h}$. Thereafter, $20 \mu \mathrm{L}$ of MTT reaction solution ( $5 \mathrm{mg} / \mathrm{mL}$ MTT in PBS; Sigma) was added to each well, and the plates were incubated at $37{ }^{\circ} \mathrm{C}$ for $4 \mathrm{~h}$. $10 \%$ SDS solution $(100 \mu \mathrm{L})$ containing $0.01 \mathrm{M}$ HCL was immediately added to each well to solubilize deposit and the plates were incubated overnight. Spectrometric absorbance was measured at $570 \mathrm{~nm}$ by a $\mu$ Quant microplate reader (Bio-Tek). Cell viability was determined relative to the control.

\subsection{Inhibition of RADA16-I against K562 Tumor Growth in Mice}

BALB/c nude mice (4-6 weeks) were obtained from the Experimental Animal Center, Sichuan University. Approximately $1 \times 107 \mathrm{~K} 562$ cells suspended in $200 \mu \mathrm{L}$ of serum-free culture medium RPMI 1,640/Matrigel mixture (1:1) were injected s.c. into the right flank of nude mice. Four days after implantation, solid tumor formed. The mice were then randomly assigned into two groups, RADA16-I treatment group and control group. Each group contained seven mice aged $5-6$ weeks. In treatment group, RADA16-I solution ( $2 \mathrm{mM}, 0.1 \mathrm{~mL})$ was injected to the brim of the tumors every 3 days. Parallel experiments were performed in control group, in which $0.1 \mathrm{~mL}$ of sterile water without peptide was injected in the same manner. Mice were sacrificed 18 days after the first treatment to measure tumor masses and to perform histological examination by $\mathrm{H} \& \mathrm{E}$ staining.

\subsection{Vascular Tube Formation Assay in vitro}

Vascular tube formation assay in vitro was performed according to the previous description [14,15]. Briefly, 96-well plates were coated with Matrigel $(0.05 \mathrm{~mL})$ and incubated at $37^{\circ} \mathrm{C}$ for $1 \mathrm{~h}$ to promote 
gelling. HUVECs suspension $\left(1.4 \times 10^{4}\right.$ cells/well $)$ were seeded on the Matrigel and treated with RADA16-I solutions at various concentrations for $9 \mathrm{~h}$. Phase-contrast microscope (Olympus IX71, Tokyo, Japan) was used to record tube formation by HUVECs.

\subsection{Statistical Analysis}

Statistical analysis was performed by using the SPSS 13.0 for windows package, and student's t test was used to determine statistical significance.

\section{Conclusions}

We have investigated the self-assembling ability of peptide RADA16-I and its effect on the growth of human leukemia cells in vitro and in vivo. AFM images showed that peptide RADA16-I molecules have excellent self-assembling ability to form nanofiber scaffolds, which have been used as a biomimetic extracellular matrix. Most importantly, the study demonstrated that RADA16-I molecules inhibit the growth of K562 tumors in nude mice though they have no cytotoxicity against cancer cells in vitro. Furthermore, we found that RADA16-I inhibited the vascular tube-formation by HUVECs without cytotoxic effect in vitro. Taken together, our data indicated that RADA16-I molecules selfassemble into nanofiber scaffolds, which could change tumor microenvironments (including vascular tubes), and inhibit the growth of tumors. This study reveals the feasibility of designing novel nanomaterials based on self-assembling systems for cancer treatment.

\section{Acknowledgements}

We would like to thank Fengqiu and Yongzhu Chen for helpful discussions. This work was supported by the "project 985" of Ministry of Education of the People's Republic of China.

\section{References and Notes}

1. Chabner, B.A.; Roberts, T.G., Jr. Timeline: Chemotherapy and the war on cancer. Nat. Rev. Cancer 2005, 5, 65-72.

2. Smith, L.L.; Brown, K.; Carthew, P.; Lim, C.K.; Martin, E.A.; Styles, J.; White, I.N. Chemoprevention of breast cancer by tamoxifen: risks and opportunities. Crit. Rev. Toxicol. 2000, 30, 571-594.

3. Weaver, V.M.; Lelievre, S.; Lakins, J.N.; Chrenek, M.A.; Jones, J.C.; Giancotti, F.; Werb, Z.; Bissell, M.J. Beta4 integrin-dependent formation of polarized three-dimensional architecture confers resistance to apoptosis in normal and malignant mammary epithelium. Cancer Cell 2002, 2, 205-216.

4. Guo, Y.S.; Jin, G.F.; Houston, C.W.; Thompson, J.C.; Townsend, C.M., Jr. Insulin-like growth factor-I promotes multidrug resistance in MCLM colon cancer cells. J. Cell Physiol. 1998, 175, 141-148. 
5. Sethi, T.; Rintoul, R.C.; Moore, S.M.; MacKinnon, A.C.; Salter, D.; Choo, C.; Chilvers, E.R.; Dransfield, I.; Donnelly, S.C.; Strieter, R.; Haslett, C. Extracellular matrix proteins protect small cell lung cancer cells against apoptosis: a mechanism for small cell lung cancer growth and drug resistance in vivo. Nat. Med. 1999, 5, 662-668.

6. Zhang, S.; Holmes, T.; Lockshin, C.; Rich, A. Spontaneous assembly of a self-complementary oligopeptide to form a stable macroscopic membrane. Proc. Natl. Acad. Sci. USA 1993, 90, 3334-3338.

7. Zhang, S.; Holmes, T.C.; DiPersio, C.M.; Hynes, R.O.; Su, X.; Rich, A. Self-complementary oligopeptide matrices support mammalian cell attachment. Biomaterials 1995, 16, 1385-1393.

8. Holmes, T.C.; de Lacalle, S.; Su, X.; Liu, G.; Rich, A.; Zhang, S. Extensive neurite outgrowth and active synapse formation on self-assembling peptide scaffolds. Proc. Natl. Acad. Sci. USA 2000, 97, 6728-6733.

9. Kisiday, J.; Jin, M.; Kurz, B.; Hung, H.; Semino, C.; Zhang, S.; Grodzinsky, A.J. Self-assembling peptide hydrogel fosters chondrocyte extracellular matrix production and cell division: implications for cartilage tissue repair. Proc. Natl. Acad. Sci. USA 2002, 99, 9996-10001.

10. Davis, M.E.; Motion, J.P.; Narmoneva, D.A.; Takahashi, T.; Hakuno, D.; Kamm, R.D.; Zhang, S.; Lee, R.T. Injectable self-assembling peptide nanofibers create intramyocardial microenvironments for endothelial cells. Circulation 2005, 111, 442-450.

11. Zhang, S.; Lockshin, C.; Cook, R.; Rich, A. Unusually stable beta-sheet formation in an ionic self-complementary oligopeptide. Biopolymers 1994, 34, 663-672.

12. Caplan, M.R.; Moore, P.N.; Zhang, S.; Kamm, R.D.; Lauffenburger, D.A. Self-assembly of a beta-sheet protein governed by relief of electrostatic repulsion relative to van der Waals attraction. Biomacromolecules 2000, 1, 627-631.

13. Caplan, M. R.; Schwartzfarb, E. M.; Zhang, S.; Kamm, R. D.; Lauffenburger, D. A. Control of self-assembling oligopeptide matrix formation through systematic variation of amino acid sequence. Biomaterials 2002, 23, 219-227.

14. Schweigerer, L.; Neufeld, G.; Friedman, J.; Abraham, J.A.; Fiddes, J.C.; Gospodarowicz, D. Capillary endothelial cells express basic fibroblast growth factor, a mitogen that promotes their own growth. Nature 1987, 325, 257-259.

15. Malinda, K.M.; Sidhu, G.S.; Mani, H.; Banaudha, K.; Maheshwari, R.K.; Goldstein, A.L.; Kleinman, H.K. Thymosin beta4 accelerates wound healing. J. Invest. Dermatol. 1999, 113, 364-368.

16. Zhang, S.; Rich, A. Direct conversion of an oligopeptide from a beta-sheet to an alpha-helix: a model for amyloid formation. Proc. Natl. Acad. Sci. USA 1997, 94, 23-28.

17. Yokoi, H.; Kinoshita, T.; Zhang, S. Dynamic reassembly of peptide RADA16 nanofiber scaffold. Proc. Natl. Acad. Sci. USA 2005, 102, 8414-8419.

18. Ellis-Behnke, R.G.; Liang, Y.X.; You, S.W.; Tay, D.K.; Zhang, S.; So, K.F.; Schneider, G.E. Nano neuro knitting: peptide nanofiber scaffold for brain repair and axon regeneration with functional return of vision. Proc. Natl. Acad. Sci. USA 2006, 103, 5054-5059. 
19. Jaffe, E.A.; Nachman, R.L.; Becker, C.G.; Minick, C.R. Culture of human endothelial cells derived from umbilical veins. Identification by morphologic and immunologic criteria. J. Clin. Invest. 1973, 52, 2745-2756.

20. Tada, H.; Shiho, O.; Kuroshima, K.; Koyama, M.; Tsukamoto, K. An improved colorimetric assay for interleukin 2. J. Immunol. Methods 1986, 93, 157-165.

(C) 2009 by the authors; licensee Molecular Diversity Preservation International, Basel, Switzerland. This article is an open-access article distributed under the terms and conditions of the Creative Commons Attribution license (http://creativecommons.org/licenses/by/3.0/). 